\title{
Relationship between elemental concentrations and top-dying disease in mangrove forest trees in the Sundarbans in Bangladesh
}

\author{
Awal, Mohd Abdul \\ Environmental Scientist, Founder \& Chief Advisor, Health \& Pollution Research Farm, New York, USA

\section{Email address:} \\ abdul_awal2004@yahoo.com
}

To cite this article:

Awal, Mohd. Abdul. Relationship between Elemental Concentrations and Top-Dying Disease in Mangrove Forest Trees in the Sundarbans in Bangladesh. Plant. Vol. 2, No. 4, 2014, pp. 41-53. doi: 10.11648/j.plant.20140204.11

\begin{abstract}
The present work has explored some of the possible environmental factors involved, focussing particularly on the relationship between the amount of top-dying in different places and the concentrations of a number of chemical elements present in the soil, in order to test the hypothesis that chemical pollution might be responsible. Nine plots were selected for sampling of soil, and from these plots 63 soil samples were assessed, mainly by ICPMS, to investigate certain parameters of the soil, such as $\mathrm{Sn}$, Exchangeable $\mathrm{K}, \mathrm{Pb}, \mathrm{Zn}, \mathrm{Sc}$, and elemental concentrations of 32 other elements. Most of the elements studied had no significant correlation with the top dying of Heritiera fomes. Survey was done to categorize different areas in terms of their intensity of top-dying within the study area in Sundarbans (the largest single tract of mangrove forest in the world). The vegetation structure was assessed in terms of tree height, bole diameter, species present, and regeneration status; and the intensity of top-dying within the plots was recorded on a rank scale basis such as trees which are not affected by top dying disease(rank-0), commonly affected by top dying disease(rank-1), moderately affected by top-dying disease (rank-2) and severely affected by top dying disease(rank-3) based on relevant maps, documents, literature, consultations with forest professionals, and surrounding peoples. This was later expressed as a semi-quantitative or rank scale of 0 to 3 respectively, so that a median rank value could be calculated and used as an index of top-dying intensity in that plot. After that, the total number of seedlings (individuals of the tree species $<1 \mathrm{~m}$ tall), and saplings (young trees $>1 \mathrm{~m}$ tall with a diameter of trunk of $<10 \mathrm{~cm}$ ), were counted within the plots. However, Sn, Exchangeable K, namely $\mathrm{Pb}, \mathrm{Zn}, \mathrm{Sc}$, were also close to significance. Sn concentration is negatively associated with top dying. Exchangeable $\mathrm{K}$ was positively associated with the tree diameter whether the top dying was severe or mild. However, the present results have showed that $\mathrm{Sn}$, Exchangeable $\mathrm{K}, \mathrm{Pb}, \mathrm{Sr}$ and $\mathrm{Zn}$ and could be directly linked with top-dying of Heritiera fomes (Sundri) in Sundarbans, probably particularly by weakening the vigour of the trees and allowing other factors such as pathological agents to attack the plants.
\end{abstract}

Keywords: Causal Factors, Elemental Concentrations, Sundri Tree, Heritiera Fomes, Mangrove, Sundarbans, People Health Problem, Top-Dying, Soil and Water Problems in Sundarbans

\section{Introduction}

Representing 2.5 percent of the world's mangrove forest (Saha, 1991), the Sundarban forest is still the largest natural single tract of mangrove forest and habitats in the world (Christensen, 1984; Seidensticker and Hai, 1983; Hussain and Karim, 1994) with $10,029 \mathrm{~km}^{2}$ area. The total area of the part of Sundarban in Bangladesh is now about 6,017 $\mathrm{km}^{2}$ (Imam, 1982; Christensen, 1984; Chaffey et al., 1985), which arose due to the eastward shift of the Ganges (Blasco, 1977; Naskar 1999; and Bakshi, 1954; Thom, 1982).
Heritiera fomes (Sundri) is the predominant tree species, supporting about $65 \%$ of the total merchantable timber (Chaffey et al., 1985, and Siddiqi, 2001). Coastal lands cover $6 \%$ of the world's land surface (Tiner, 1984). Coastal and wetlands everywhere are under threat from agricultural intensification, pollution, major engineering schemes and urban development, (UN-ESCAP 1987; 1988).The mangrove zone of Bangladesh is about $710 \mathrm{~km}$ long including on several tiny islands In the present day the Indo-Malayan mangroves are confined to Sundarban reserved forests, mainly in Bangladesh. Figure 1.0: Map showing the administrative districts of Bangladesh, 
including the location of the Sundarbans (the shaded area in the south-west of the country). But at the arrival of British rule in 1765 , the Sundarbans forests were double their present size and significant exhaustion of the growing stock led to dwindling by $40 \%-45 \%$ between 1959 and 1983 (Chaffey et al., 1985). For example, through tourism to coastal ecosystems in the Maldives, fish lives had shrunk and also have been polluted by the combined effects of agricultural run-off and siltation, urban sewage, and industrial pollutants (Government of Maldives 1994). A large number of species of fauna and flora have vanished from the global mangroves (Seidensticker and Hai, 1983). In the U.S.A, and Australia also, (Rahman, et al., 2003). mangroves are being adversely affected by both nearby developments and pollution problems (Peters et al., 1985). Coastal biological resources have been depleted by heavy metal contamination in soil and commercial activities, including poison and blast fishing (Jones, 1992). In addition, pollution from shipping, in particular oil, and in some areas the discharge of toxic wastes, had adversely affected the marine environment (UNESCAP 1988). The Sundarban mangrove forest is located mainly at the southern portion of the Gangetic delta bordering on the Bay of Bengal of Bangladesh (Blasco, 1977; Naskar 1999; and Bakshi, 1954; Thom, 1982, Figure1.0).

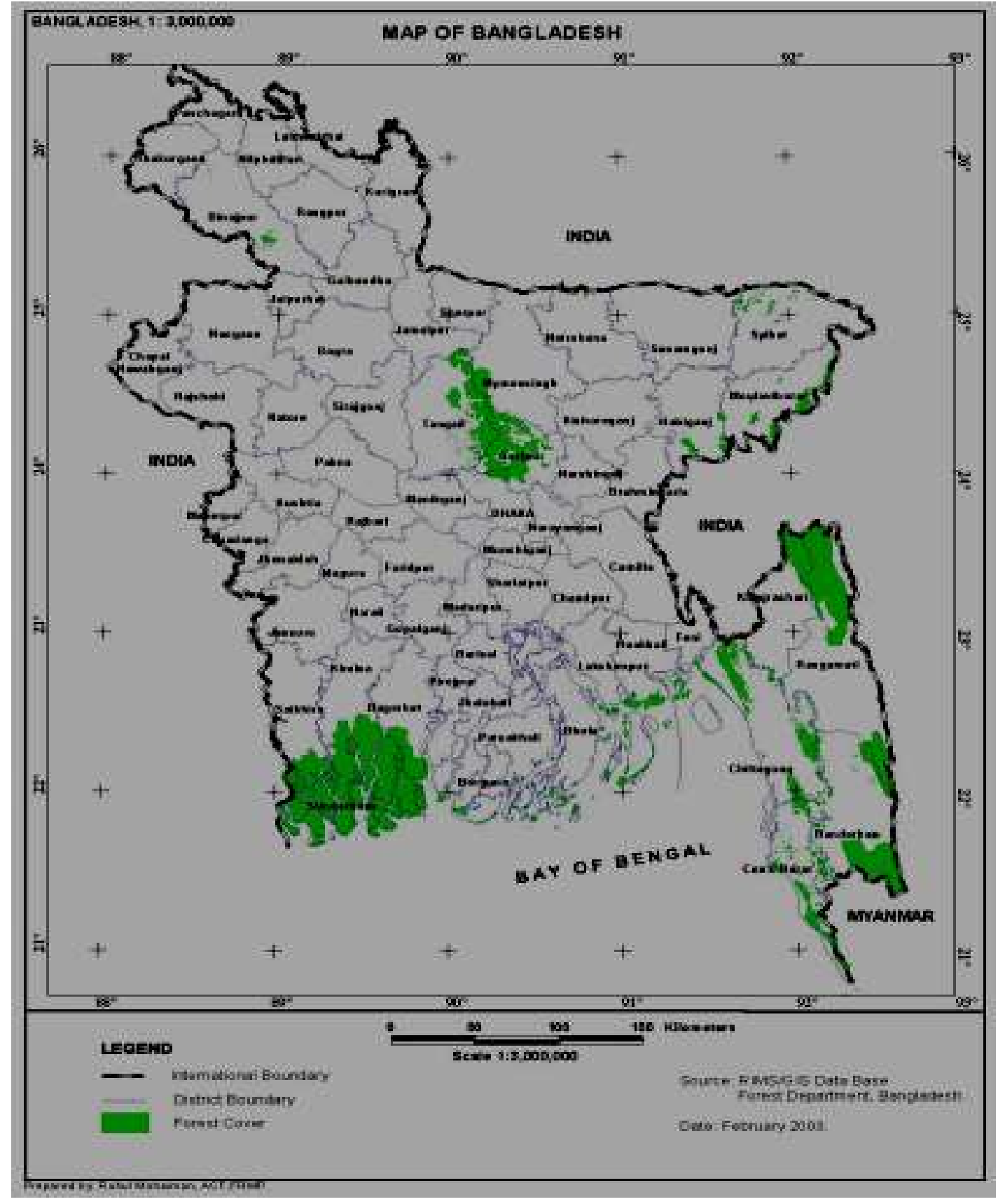

Figure 1.0. Map showing the administrative districts of Bangladesh, including the location of the Sundarbans. 


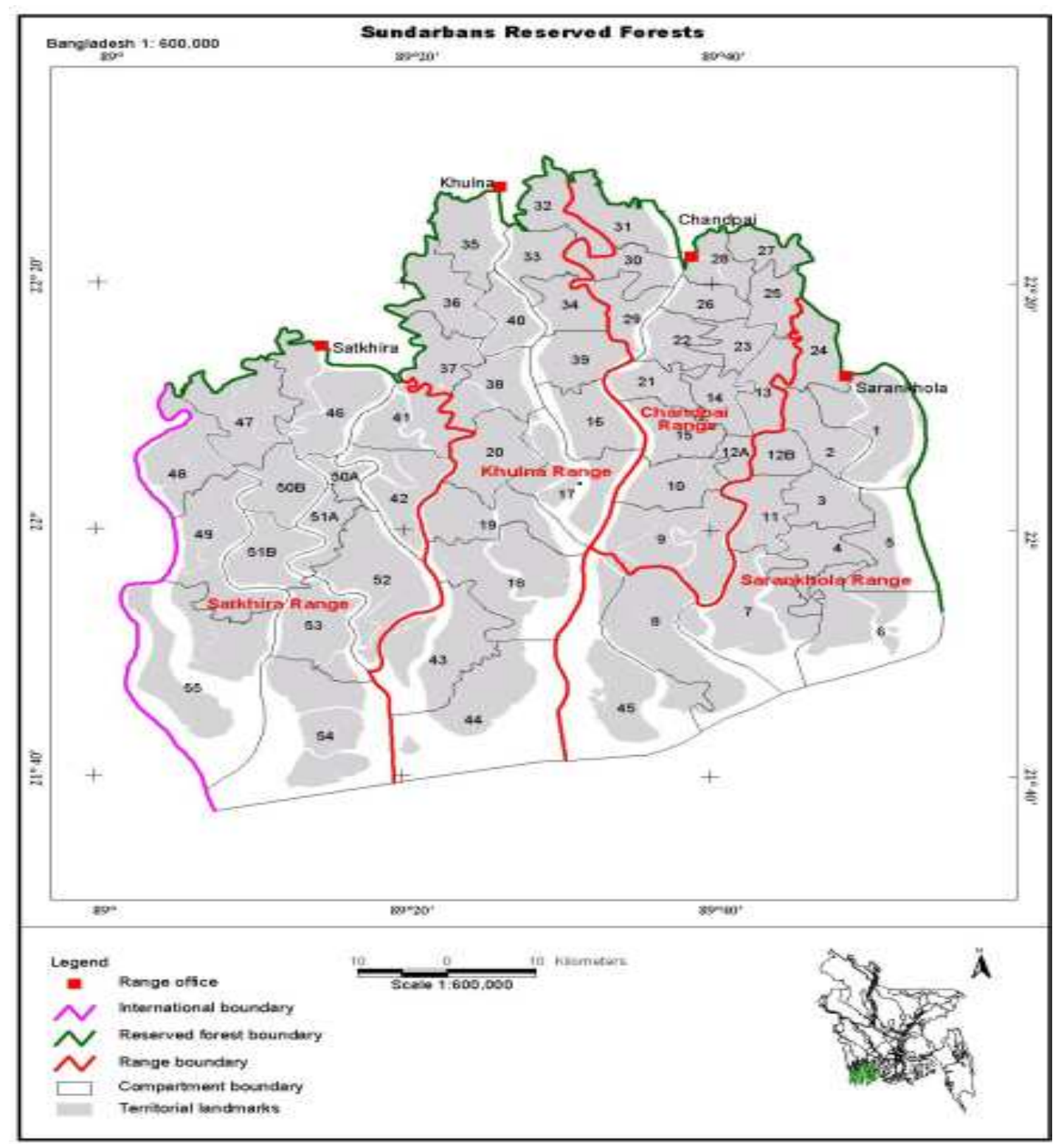

Figure 2.0. Map Shows compartment numbers and Ranges of Sundarbans Reserved Forest.

It occupies a flat deltaic swamp rarely exceeding 0.9 to 2.1 $\mathrm{m}$ above the sea level and most of the area is under water during the high spring tides of the monsoon and the major portion of land is a low plain with maximum $10 \mathrm{~m}$ height above mean sea level (FAO, 1994). Sundarbans is subdivided into 8 blocks (Rahman, 2003) and further subdivided into 55 compartments (Figure 2.0), varying in size from 4000-16,000 ha (Tamang, 1993), depending on the height classes \& stocking conditions of the forest trees to be shown below as (figure:2.0).

\subsection{Location}

The forest lies just south of the topic between $21^{\circ} 38^{\prime}-$ $22^{\circ} 30^{\prime}$ North latitudes and $89^{\circ} 0^{\prime}-90^{\circ} 0^{\prime}$ East longitudes. Within the total areas of the Sundarbans, Heritiera fomes constituted $63.8 \%$ among the total tree vegetation (Chaffey et al., 1985).

\subsection{Overview of Environmental Factors Affecting the Sundarban}

Sundarbans mangrove forests usually create thick, organically rich sediments as their substrata. Most of the substrata in the tropics except under deltaic environments consist of mangrove peat which mainly derives from mangrove roots (Fujimoto et al., 1996; and Siddiqi et al., 1993). Sundarban mangrove forests have great belowground productivity and play a significant role in carbon concentration not only above ground but also below ground. Mangrove ecosystems therefore provide a unique and valuable range of resources and services. Thus a great number of birds, mammals, fishes and invertebrates utilize mangroves like Sundarbans during at least one part of their life cycle (Siddiqi et al., 1993). 


\subsubsection{Soil/Sediment}

The soils of the Ganges delta are unripened, slightly calcareous, tidally flooded, grey, massive, alkaline, clayey muds with low $(<2 \%)$ organic matter content (Anon, 1975; Hassan, 1988), although localized depressions may contain higher amount $(>50 \%)$ of organic matter (Anon, 1975). The Sundarbans soils are rich in clay and silt content, and have been derived allochthonously from deltaic floodplain alluviums and autochthonously from tidal marsh materials consisting mainly of organic matter (peat deposition) and, to a lesser extent, from bicarbonates from shell-farming marine / estuarine organisms (Choudhury, 1962). Large amount of weatherable minerals such as chemical elements, carbonates, and feldspars, are present in the silt fraction of these soils, which protect them from turning into acid sulphate conditions after drainage improvement (Anon, 1975). Moreover, the high clay content, high CEC and high $\mathrm{pH}$ of these soils are indicative of their potential fertility with the $\mathrm{pH}$ averaging 8.0 (Christensen, 1984). The Sundarban soil is classified as Typic Haplaquents (Anon, 1975; Gopalswamy and Chowdhury, 1973). In the eastern part of Sundarbans the surface soil is soft and fertile, whereas it is harder and less suitable for tree growth in the west (Choudhury, 1968). The top soil horizon consists of silt and clay loam over alternating horizons of clay and sand (Choudhury, 1962). The surface is clay except on the seaward side of islands in the coastal limits, where sandy beaches occur. Alluvial deposits were geologically very recent and those were deep, poorly drained, fine textured, and had mineral compositions which were traceable to the bed rock parent-material of the gneissic mountains of the Himalayas. However, this surface soil was dominantly clay overlain with thin layers of silt delivered annually by monsoon floods. In the more eastern Sundarbans, where the silting process provided fertile nutrients, the delta forests are more highly productive and compacted, de-watered clays which tend to selectively concentrate chlorine (Landsberg, 1997). The carbonate initially present in the sediment is lost rapidly due to lateral decalcification (Ponnamperuma, 1965). The moisture content of mangrove soils has been reported to vary from $43 \%$ to $196 \%$ by dry weight of the soil by Giglioli and King, (1966, 1995), and a similar range of values has been reported for surface soil moisture content of about $28.6 \%$ to $43.3 \%$ by dry weight (Faizuddin, 2003). In the natural process, land in the Sundarban is formed by the silting up of the interlocking creeks, forming islands that eventually connect and are permanently above the water level and become slightly acidic (Own observation, 1993 -1997). As a result, soil fertility has declined, and many rivers have become moribund (Mitra, 1954). The Sundarbans is therefore a dynamic natural resource, which may be affected by changing chemical and physical properties of soils which could affect forest growth. For example, working in Indonesia, the physico-chemical factors of mangrove soil were investigated and the soil $\mathrm{pH}$, the carbonates of salt and the content of humus in mangrove soils were found to be very important for species association (Navalkar and Bharucha, 1949), and this might be expected to be the same in the Sundarbans. Nitrogen, phosphorus and sulphur concentrations in soil have also been found to affect mangrove zonation (Faizuddin, 2003).

\subsubsection{Hydrology and Tides}

A large part of the Sundarban remains above tidal level during the lean season, while only a part is flooded during the spring high tides and a small part in the South and West is tidally flooded throughout the year. However, the whole of the Sundarbans becomes submerged during high monsoon tides. The depth and duration of tidal inundation depends on factors including: (1) the distance from the sea and the main river; (2) local relief; (3) the general elevation of the area; and (4) the load content of the inundating water. These factors also influence the ecological conditions of a site within the Sundarbans. The Sundarbans are crisscrossed by a network of interconnecting channels (Islam, 2003) and the main rivers are the Baleswar, Passur, Sibsa, Kobadak, Jamuna and Raimangal. The Baleswar and Passur rivers are linked with the Ganges through the GoraiModhumati, and the Arial khan rivers. The Sibsa and Kobadak rivers are not connected with the main flow of the Ganges during the lean season. The Baleswar, washing the eastern fringe of the Sundarbans, receives the bulk of the Ganges water while the Passur shares only a few cusecs during the lean season (Own observation, 1993-97).

\section{Method}

In this chapter the various field and laboratory methods used in this study will be discussed.

\subsection{Field Sampling Methods}

The Sundarbans Reserved Forest is located at the south west corner of the Ganges River Delta close to the Bay of Bengal, mainly on the sea-shore line, river banks, channels, and small creeks. The location of the Sundarbans within Bangladesh has been shown in (Figure 1.0).

\subsection{Site Selection and Location of the Study Area}

General reconnaissance of possible sites was made by visiting all the possible regional areas before categorizing and selecting plots for sampling. It was decided to sample from the Chandpai area which is the mostly human accessible and ecologically polluted area. Three compartments from this regional area (range), namely numbers 26, 28 and 31, were selected because they were believed to represent a range of severity of top dying disease, based on relevant maps, documents, literature, consultations with forest professionals, and surrounding peoples. The location of these compartments within the Chandpai area, and the location of this area in the wider Sundarbans is shown in Figure 3.0. Among the three compartments, compartment number 26 was selected as an 
area highly affected by top-dying, where most of the trees were affected severely. Compartment 26 had pronounced human activities, and also in places is undergoing rapid housing development involving extensive construction activities due to the presence nearby of the Range HQ office in Chandpai. Compartment number 28 was selected as a moderately affected area. This compartment has various human activities including boat making grounds, football-playing grounds, and cattle-grazing fields, all types of major soil erosion, a moderate amount of construction activities and the presence of communities of fishermen. Compartment number 31 was chosen as being relatively little affected by top-dying disease. Of the three chosen compartments, the nearest compartment to Mongla port is compartment 31 , with comparatively modest human activities, but which nonetheless involve clear-cutting of natural vegetation, replanting with other species rather than mangrove or other native species, all types of soil erosion, and construction activities present. Within each of the three compartments, detailed observations of the regeneration sampling of soil and water took place within three $20 \mathrm{~m} \mathrm{x}$ $20 \mathrm{~m}$ plots, chosen to reflect a range of top dying intensities (High, medium and Low).

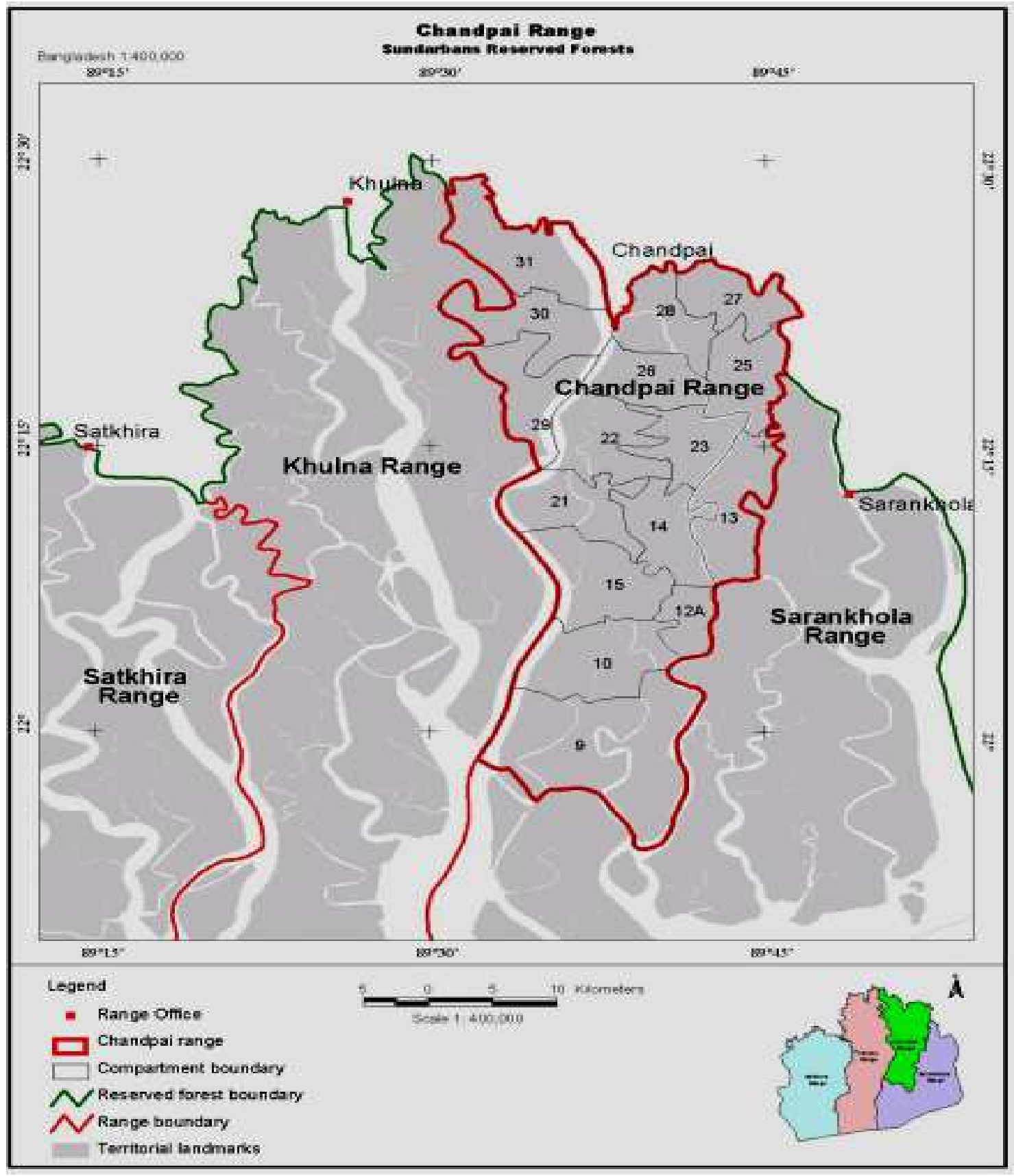

Figure 3.0. Map showing the location of the numbered compartments within the Chandpai area, and the position of this area relative to other parts of the Sundarbans in Bangladesh (darker shaded area). 




Figure 4.0. Photograph showing the Sundarbans forest trees and understory vegetation. The adult trees behind the author are of Heritiera fomes. The forest floor shows dead leaves from trees affected by top-dying during sample collection of this research in Sundarbans.

The sampling was conducted in a randomized block design (Figure: 4.0), in that a plot was sited within a particular top-dying intensity block including understory vegetation of Sundarbans, but the precise location of that plot was randomized so as not to bias the detailed data collection. Thus in total nine plots were sampled, representing a range of top-dying intensities. Intensive field data collection was made among these nine selected plots.
Observations were performed from observation towers during low and high tides, also traversing the forest floor and vegetation on foot, as well as using a speed boat, trawlers, country-boats, and a launch as required to gain access. All sampling was accompanied by Deputy Rangers, Foresters, and Forest guards armed with a rifle from the local office, Chandpai rang, Bangladesh Forest Department, to prevent a fatal attack by a Bengal tiger (Panthera tigris). 
Fieldwork was performed in October, 2003 to March, 2004. Locations of sampling points were determined using a Global Positioning System with a precision of 5-10 m. For one typical plot, in compartment 31 , the altitude was recorded as $4.4 \mathrm{~m}$ above sea level.

\subsection{Vegetation Recording Methods in the Field}

Within each of the nine $20 \mathrm{mx} 20 \mathrm{~m}$ plots, each adult tree was assessed for three parameters. The diameter at $1 \mathrm{~m}$ height was recorded (in $\mathrm{cm}$ ) by using a measuring tape or slide callipers depending on girth. The tree height to the top of the crown was determined mainly by ocular estimation but some heights were checked by using Clinometers at a set distance of $20 \mathrm{~m}$ to test the accuracy of such ocular estimations. Finally, the status of the tree in respect of the amount of top-dying was assessed by using a four point qualitative scale of intensity, namely; not affected, little affected, moderately affected or highly affected by topdying. This was later expressed as a semi-quantitative or rank scale of 0 to 3 respectively, so that a median rank value could be calculated and used as an index of top-dying intensity in that plot. After that, the total number of seedlings (individuals of the tree species $<1 \mathrm{~m}$ tall), and saplings (young trees $>1 \mathrm{~m}$ tall with a diameter of trunk of $<10 \mathrm{~cm}$ ), were counted within the plots. Care was taken to ensure that trees, saplings and seedlings were not counted more than once or missed in the counting process. After recording, adult trees were marked with white chalk to segregate those marked trees from other trees, seedlings and saplings; red paints were applied to all seedlings and saplings as they were recorded (Table: 3.0).

\subsection{Soil and Water Sampling Methods}

As stated above, from the three selected compartments, a total of nine plots of $20 \mathrm{~m} \times 20 \mathrm{~m}$ were selected. From each of these plots, seven soil samples were collected (Figure: 4.0); one from the centre of the plot, four (one each) from all the corners, and two from the middle sides of the plot. Therefore a total of 63 soil samples were taken (Figure: 4.0). Also nine water samples were collected from nearby rivers, creeks or channels, one from the area of each of the sampled plots. Soil samples were collected from 0-30 cm soil depth by using a stainless steel spatula and steel cylinder $(d=5.25 \mathrm{~cm})$, and all soil samples were kept in sealed plastic bags. Water samples were collected directly in pre-cleaned plastic-containers. Marking and labelling was performed with a detailed description of the selected sampling site on both the soil-containing plastic bags and water containers, and preserved in portable coolers until arrival at the laboratory at Dhaka University for initial chemical analysis. This field sampling method followed the W.H.O, U.K, and E.P.A systems of standard laboratory and field sampling principles, rules and regulations. Rainfall for the area during sample collection was not notably different from the respective monthly averages for the Sundarbans of recent years (Awal, 2007); there was no heavy intensity of rainfall within one month before sampling (Awal, 2007). The majorities of soil analyses have been performed at Bradford University using ICPMS, and there are detailed later. However, certain analyses of the soil, and all analyses of water, had to be conducted at Dhaka University, shortly after collecting the material. The procedures used there are indicated in the subsections that follow.

\subsection{Sulphur (S) Determination}

$10 \mathrm{~g}$ of air-dried and sieved soil sample was weighed by an analytical balance and $50 \mathrm{ml}$ of $\mathrm{Ca}\left(\mathrm{HPO}_{4}\right)_{2} \cdot \mathrm{H}_{2} \mathrm{O}$ was added, and was placed in a graduated glass beaker for extraction. The suspension was stirred 5-11 times using a glass rod, and was then transferred to a $100 \mathrm{ml}$ cleaned plastic bottle and made up to volume with deionised water. Then, $2 \mathrm{ml}$ extracted sample was placed into a volumetric flask using a $2 \mathrm{ml}$ glass pipette and added $6 \mathrm{ml}$ of $\mathrm{M} \mathrm{HCl}$ was added, after that $3 \mathrm{ml}$ of Tween- 80 solutions was added to get a white colour, and distilled water was added up to the $25 \mathrm{ml}$ of the volumetric flask. Shaking was done five times for one hour each time by a mechanical shaker, and the solution was filtered by thick, medium speed paper with a high retention (Whatman Number 42), before taking a reading. The reading was taken by using of Tween- 80 solutions was added to get a white colour, and distilled water was added up to the $25 \mathrm{ml}$ of the volumetric flask. Shaking was done five times for one hour each time by a mechanical shaker, and the solution was filtered by thick, medium speed paper with a high retention (Whatman Number 42), before taking a reading. The reading was taken by using the Spectrophotometer (Model: 6100, Jenway Company, at $670 \mathrm{~nm}$ ). Water sample determinations were also taken by using the same instrument and procedures.

\subsection{Soluble Nitrogen $\left(N_{2}\right)$ Determination by Digestion Apparatus Method}

$10 \mathrm{~g}$ of air-dried and sieved soil sample were taken and added to $50 \mathrm{ml}$ of distilled water and placed in a beaker for extraction. Shaking was done by a mechanical shaker for one hour. The extractant was filtered by thick, medium speed filter paper with high retention (Whatman Number, 42-Ashless, $11 \mathrm{~cm}$ ). Filtration was done by washing the sample 9-14 times, and ammonium acetate was added to a $100 \mathrm{ml}$ volumetric flask or cleaned-plastic bottle. Titration of solution was done with $0.0109 \mathrm{M} \mathrm{H}_{2} \mathrm{SO}_{4}$ by a micro burette. Finally from the difference between initial and final burette readings, the soluble Nitrogen value was determined.

\subsection{Total Nitrogen Determination by Kjeldahl Digestion Method}

The total $\mathrm{N}$ content of soils was estimated using Kjeldahl acid digestion method. $2 \mathrm{~g}$ of air dried and sieved soil sample was weighed and added to $20 \mathrm{ml}$ of $\mathrm{H}_{2} \mathrm{SO}_{4}$ using 10 $\mathrm{ml}$ of distilled water that was placed in a beaker and heated 
for 10 minutes at a low temperature. After cooling, the digestion mixture: $\mathrm{K}_{2} \mathrm{SO}_{4}$ or $\mathrm{Na}_{2} \mathrm{SO}_{4}$ plus $\mathrm{Cu}_{2} \mathrm{SO}_{4}$ and Selenium were added in the proportions of 100:10:1. Then the sample was heated at a high temperature $\left(102-103^{\circ} \mathrm{C}\right)$ for an hour, and after cooling, samples were placed in a 100 $\mathrm{ml}$ volumetric Kjeldahl flask and made up to the mark. Samples were transferred from the Kjeldahl flask to a $100 \mathrm{ml}$ plastic bottle for using in titration. Ten $\mathrm{ml}$ of $\mathrm{NaOH}$ solution was used for the digestion with $10 \mathrm{ml}$ of Nitrogen digestion extract solution and passed through a small funnel into the reaction-condenser of the digestion apparatus. In the bottom stand, a mixed indicator of methyl red, bromocreasol, and boric acid, were added. Heating was done at $103-104{ }^{\circ} \mathrm{C}$, until the solution colour (dark brown) turned to blue. Titration into the mixture was done with $0.0109 \mathrm{M} \mathrm{H}_{2} \mathrm{SO}_{4}$ by a micro burette. Finally from the difference between initial and final burette readings, the total Nitrogen value was determined.

\subsection{Soil and Water EC Determination by EC Meter}

$10 \mathrm{~g}$ of soil was placed in a glass beaker, and $50 \mathrm{ml}$ of distilled water was added to the soil. Shaking was done by a mechanical shaker, and stirring was also done 5-7 times to ensure thorough mixing of the mixture. The mixture of soil solution was left overnight for it to reach its stable suspension position phase. Finally the reading of soil EC was recorded by using an EC meter.

\subsection{Soil and Water pH Determination by $\mathrm{pH}$ Meter}

$20 \mathrm{~g}$ of soil was weighed using an analytical balance and placed into a graduated glass beaker. $50 \mathrm{ml}$ of distilled water was added to the soil. Shaking was done, and stirring was also done 5-7 times to ensure through mixing of the mixture. The mixture of soil solution was left overnight for it to reach its stable suspension position phase. The soil $\mathrm{pH}$ was then recorded by $\mathrm{pH}$ meter (model; 3305; Jenway Company Ltd).

\subsection{Particle Size Analysis of Soil by Hydrometer}

Each dried soil sample was ground to a powder using a pestle and mortar, and then sieved through a $2 \mathrm{~mm}$ sieve, 40 $\mathrm{g}$ of air dry fine earth fraction of the sieved soil was then placed into a tall $800 \mathrm{ml}$. graduated glass beaker; and $5 \mathrm{ml}$ of hydrogen peroxide solution $\left(\mathrm{H}_{2} \mathrm{O}_{2}\right)$ was added and the mixture was heated for 10 minutes on a hot plate until the copious frothing cases, and when all frothing was finished, boiling for a few minutes to destroy excess peroxide solution. $100 \mathrm{ml}$ of distilled water was then added to the sample, as well as $100 \mathrm{~g}$ of Calgon (sodium-hexametaphosphate) to speed up the chemical reaction, and then transferred contents of the beaker to the mechanical stirrer for 10 minutes. After that it was left overnight in the laboratory for it to reach its stable suspension position phase. Subsequently, the suspension was transferred to the specially graduated cylinder and filled to the lower mark with distilled water with the hydrometer in place, and with a one-litre measuring cylinder filled to the $1000 \mathrm{ml}$. marked without the hydrometer in place. Further shaking was done by a plunger for 1 minute. A blank reading was recorded by hydrometer after 40 seconds. Two hours after taking this first reading, again transferred to the $800 \mathrm{ml}$. beakers and marked at $10 \mathrm{~cm}$. from the base, having stirring for 5 minutes the second reading was taken by hydrometer. During procedures for determination of soil particle size analysis, the temperature was always maintained at $29^{\circ} \mathrm{C}$ (Black, et al., 1965). The particle size analysis was then calculated using the formula.

\section{Soil particle size formula $=\left[\left\{\left(\mathrm{H}_{1}-\mathrm{H}_{0}\right) \times 20.3\right\} \%\right.$ Weight of dry soil $]$,}

where hydrometer reading $=\left(\mathrm{H}_{1}\right)$, and blank hydrometer reading $\left(\mathrm{H}_{0}\right)$.

\subsection{Moisture Percentage of Soil}

Approximately $50 \mathrm{~g}$ of soil was sieved by a $2 \mathrm{ml}$ sieve. The sieved material was then weighed and heated to $105^{\circ} \mathrm{C}$ for 24 hours to dry it completely. The dry soil was then reweighed and the difference in weights gave the weight of moisture. This amount of moisture was expressed as a percentage of the original wet soil weight.

\subsection{Statistical Analysis}

Comparisons of the strength of relationship between two variables were assessed by correlation: the Pearson's product-moment correlation coefficient where both variables were fully quantitative or the Spearman's rank correlation coefficient where the top-dying index was one of the variables. In the case of the Spearman's coefficient, the probability of the outcome was determined by using the approximation to a t-statistic appropriate to these tests (Sokal and Rohlf, 1981). Occasionally, a Pearson's correlation coefficient was calculated where top-dying was one of the variables, in order to check on the extent of the difference between the rank and quantitative versions for these data. Data on frequencies of seedlings or saplings in each of the plots and compartments were tested by $x^{2}$ contingency (Table: 3.0) analysis to determine whether there was an association between the selected plot type (severely, moderately or little affected by top-dying) and the three chosen compartments.

A similar consideration of the different compartments as comprising one factor, and the plot type as a second, was used to test the pattern of elemental concentrations and other variables by a 2 -factor analysis of variance test with replication. This allows an assessment of the significance, not only of the two factors separately but also of the interaction term linking the two factors. It should be noted 
that the plot type was not a strictly controlled factor, since the three categories of top-dying intensity were relative to each other within any one compartment and might not have been exactly equivalent between the three categories; interpretation of the results from these tests therefore needs to bear this in mind. MINITAB Release 14 Statistical Software has been used for windows on CD-ROM, 2004 edition for all data analysis, both statistical and graphical, except for those produced automatically by the Excel package attached to the ICPMS.

\section{Results}

The results of the analyses of the basic soil and water parameters such as percentage moisture content, $\mathrm{pH}$ and EC are presented in Table (1.0) below. It is observed from Table (1.0) that the moisture content of soil is quite low with the average of $21.95 \%$ but nowhere exceeding 30.245 .
This contrasts with the moisture content thought to be necessary for mangroves of $47 \%$ minimum, usually much higher. For example, the moisture content of mangrove soils has been reported to vary from $43 \%$ to $196 \%$ by dry weight of the soil by Giglioli and King (1966, 1995), and a similar range of values has been reported for surface soil moisture content of about $28.6 \%$ to $43.3 \%$ by dry weight (Faizuddin, 2003).

The present results are less than half of this (on average), suggesting that this will be adversely affecting the survivorship of the species in Sundarbans. Whether the percentage moisture content value is reflected in the amount of top-dying was tested by a Spearman's rank correlation co-efficient, and found to be significant (Awal, 2007). There was little variation in $\mathrm{pH}$ values neither of soil or water nor, apart from one anomalous result, for CEC of water. However, the CEC values for soil are lower for compartment 28 than for the other compartments.

Table 1.0. Results of various parameters of soil and water samples taken from the selected plots. Values are means of soil or water samples.

\begin{tabular}{cccccccc}
\hline Plot No. & Comp. No. & \% M.C. of soil & pH of soil & $\begin{array}{c}\text { CEC of soil } \\
\left(\mathbf{x 1 0} \mathbf{3}^{3}\right.\end{array}$ & $\begin{array}{c}\text { Soil Particle } \\
\text { size }(\boldsymbol{\mu})\end{array}$ & pH of water & CEC of Water \\
\hline 1 & 26 & 23.91 & 7.54 & 36.4 & 12.69 & 7.11 & 19480.0 \\
2 & 26 & 25.00 & 7.53 & 44.4 & 9.64 & 6.94 & 17580.0 \\
3 & 26 & 30.24 & 7.61 & 10.3 & 11.67 & 7.27 & 18850.0 \\
1 & 28 & 13.57 & 7.51 & 7.8 & 12.69 & 7.69 & 17480.0 \\
2 & 28 & 20.40 & 7.71 & 3.9 & 11.67 & 7.47 & 18250.0 \\
3 & 28 & 20.71 & 7.49 & 9.2 & 13.20 & 7.45 & 19140.0 \\
1 & 31 & 13.85 & 7.42 & 31.6 & 11.67 & 7.27 & 17300.0 \\
2 & 31 & 21.95 & 7.39 & 31.2 & 12.18 & 7.41 & 17790.0 \\
3 & 31 & 23.91 & 7.52 & 25.6 & 11.67 & 7.22 & 17420.0 \\
\hline
\end{tabular}

Table 2.0. General Linear Model for the Soil Nutrients parameters in Sundarbans: Analysis of Variance results, testing for the two factors of Compartment and Plot, together with their interaction. Values given are the F-results together with probability levels. (Significant results are indicated with asterisks). (Key:NS: $p>0.05 * *, p<0.01 ; * * *, p<0.001)$.

\begin{tabular}{|c|c|c|c|}
\hline Soil Nutrients Element & Compartment F $(2,46)$ & Plot F $(2,46)$ & Interaction $F(4,46)$ \\
\hline $\mathrm{Na}$ (Sodium) & $4.65, \mathrm{p}=0.014 * *$ & $2.14, p=0.13, \mathrm{NS}$ & $1.23, \mathrm{p}=0.31, \mathrm{NS}$ \\
\hline Exc. $\mathrm{Na}$ & $3.47, \mathrm{p}=0.039, * *$ & $0.22, p=0.80$, N.S & $1.08, p=0.38$, N.S \\
\hline Soluble-Na & $3.77, p=0.031 * *$ & $2.20, p=0.12$, N.S. & $0.17, \mathrm{p}=0.95, \mathrm{NS}$ \\
\hline Soil pH & $11.67, \mathrm{p}=0.000 * * *$ & $2.71, \mathrm{p}=0.07 * *$ & $7.46, \mathrm{p}=0.000 * * *$ \\
\hline S (Sulphur) & $4.51, \mathrm{p}=0.016^{* *}$ & $0.32, p=0.73$, N.S. & $1.86, \mathrm{p}=0.13, \mathrm{~N} . \mathrm{S}$ \\
\hline Ca Calcium & $0.37, p=69$, N.S & $2.17, p=0.13$, N.S. & $1.60, p=0.19$, N.S. \\
\hline (Soluble) K (Potassium) & $1.67, p=0.20$, N.S. & $0.67, p=0.52$, N.S. & $1.64, p=0.18$, N.S. \\
\hline Exc. K (Exchangeable - Potassium) & $5.15, \mathrm{p}=0.01 * *$ & $1.15, p=0.33$, N.S. & $0.80, p=0.53$, N.S. \\
\hline N2 (Nitrogen) & $0.63, p=0.54$, N.S. & $0.70, p=0.50$, N.S. & $1.02, p=0.40$, N.S. \\
\hline $\mathrm{Fe}$ ( Iron) & $0.38, \mathrm{p}=0.69, \mathrm{NS}$ & $1.58, \mathrm{p}=0.22, \mathrm{NS}$ & $0.74, p=0.57, \mathrm{NS}$ \\
\hline
\end{tabular}


Table 3.0. Frequency of seedlings of all tree species combined in each of the nine plots sampled.

\begin{tabular}{ccccc}
\hline $\begin{array}{c}\text { Compart-ment } / \\
\text { Plot }\end{array}$ & 26 & 28 & 31 & Totals \\
\hline 1 & 1261 & 1440 & 625 & 3326 \\
2 & 1326 & 1501 & 1430 & 4257 \\
3 & 1455 & 1575 & 1830 & 4860 \\
Totals & 4042 & 4516 & 3885 & 12443 \\
\hline
\end{tabular}

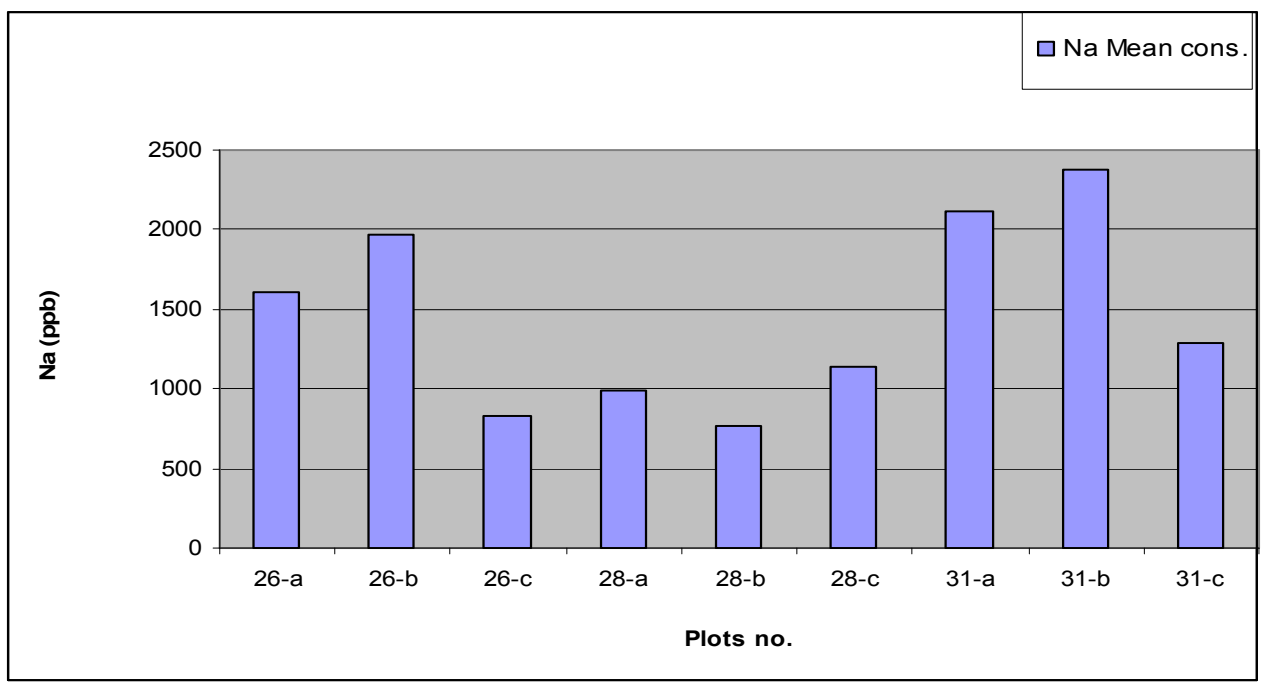

Figure 5.0. Bar chart of the average Na concentrations in the three compartments (26, 28 and 31) sampled in the Sundarbans, with three plots in each compartment.

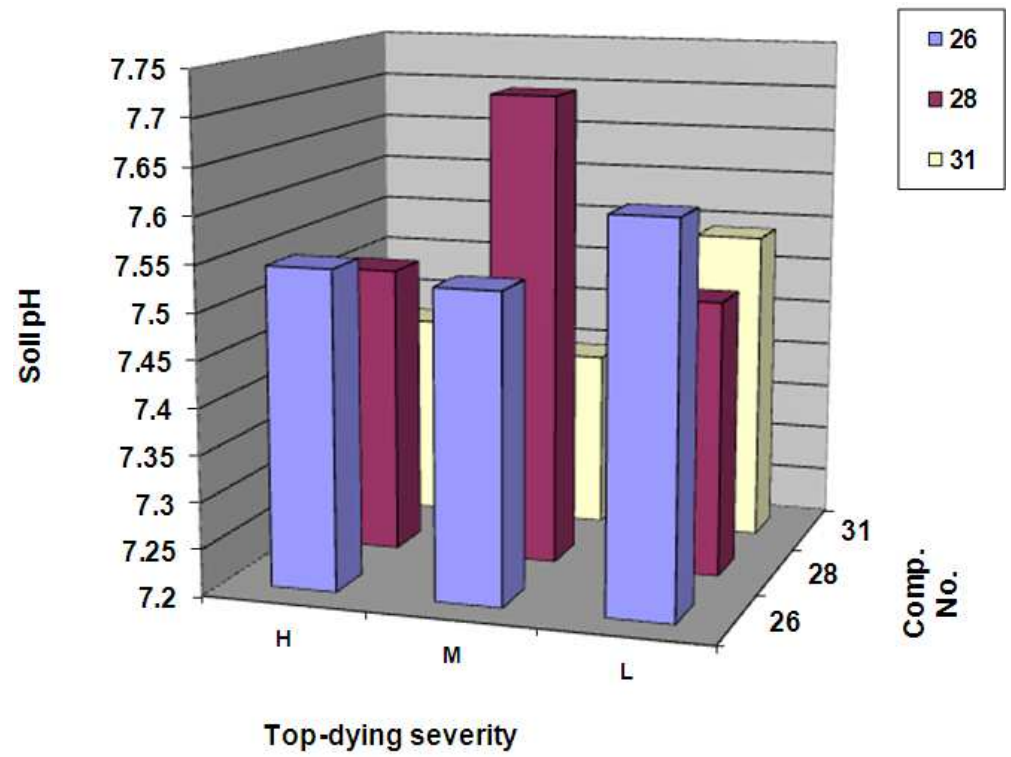

Figure 6.0. 3-D bar chart for the analysis of soil pH in the three compartments $(26,28$ and 31$)$ sampled in the Sundarbans, with three plots in each compartment.

The results from the analyses of soil parameters (Table 2.0) show many of the parameters tested to be markedly different in the different compartments but, except for soil $\mathrm{pH}$, not to vary significantly either plot in or the interaction term. Soil $\mathrm{pH}$ was, interestingly, highly or very highly significant with both factors and the interaction.

It is not surprising that there are differences between the three compartments, as they had been selected in order to demonstrate a range of circumstances that might contribute to top-dying, such as nearness to human activity. As an example of the results shown in respect of this factor, Figure: 5.0 shows a bar chart of the average $\mathrm{Na}$ values in the three compartments. It indicates that the compartments could be ordered in the sequence of 28,26 , and 31 with respect to this parameter, which corresponds with their 
location and how close they are to the coast line.

The fact that there is no significant difference between plots for any parameters (other than $\mathrm{pH}$ ) may be an indication that there is little variation in these parameters over the relatively small distances between plots; or the selection of plots based on top-dying has not selected for variation in these parameters because they are not correlated with the amount of top-dying. It is interesting that there were no significant interactions (apart from soil $\mathrm{pH})$.

This indicates that the effects evident between compartments can be considered independently of any plot effects-possibly operating at a broader geographical scale. Since soil $\mathrm{pH}$ showed significance in interaction as well as for the two factors separately, a 3-D bar chart is shown in Figure 6.0 to demonstrate how the $\mathrm{pH}$ is varying. In general, it would appear that the higher the $\mathrm{pH}$ value, the higher the amount of top-dying, although there is one result which does not fit with this trend. The pattern of variation between compartments is not consistent for the medium top-dying plots, but is consistent when comparing plots 1 and 3 in each compartment -compartment 31 having the highest $\mathrm{pH}$. There were no significant variations in any of the parameters for the water samples, for compartments or for plots, although water $\mathrm{pH}$ was close to significance when comparing between plots (Table: 6.0).This presumably implies that the water characteristics were quite consistent between different locations. This is, however, surprising given the significant differences in soil results in Table: 2.0; for example, one might have expected water $\mathrm{Na}$ concentrations to vary in similar manner to soil $\mathrm{Na}$ values, since most of the soil Na has probably derived from that brought in by sea water. It is possible that soil $\mathrm{Na}$ reflects historical differences between compartments that are no longer evident in present day-water, i.e that water characteristics have changed notably in more recent periods.

\section{Final Conclusions}

Although there were only a few individual chemical elements which showed significant correlations with the amount of top-dying, there was evidence of elevated heavymetal concentrations of many elements in the Sundarbans, which are likely to contribute to the increase in top-dying observed. There were also significant differences between different areas in the Sundarbans, and evidence of water supply problems to the system. Therefore, it is concluded that several factors are responsible for this increase in topdying, rather than one specific factor only.

\section{Acknowledgements}

My research work was supported financially by the Peoples' Republic of Bangladesh and the Asian Development Bank (ADB), whom I thank. Particular thanks are due to the ADB head office, Manila for their support and help. I thank sincerely Dr. W.G.H. Hale
(Principal Supervisor), University of Bradford, UK, Professor Mike Ashmore (Technical Supervisor), University of York, UK and Dr. P.J. Hogarth for their advice and comments on the work; Dr. Ben Stern and the staff at the Analytical Centre, Bradford, for their help with the ICPMS analyses; Professor Sirajul Hoque, Mustafa (lab Technician)and staff at Dhaka University for providing facilities; and staff of the Forestry Service, Bangladesh Government, for field assistance. Moreover I indebted to my beloved parents ( Munshi Aowlad Hossain, Mrs. Ashrafunness), my wife (Dr. Shahanaj Khatun), my son (Munshi Tasneem Redowan), my daughter (Marwa Ashra), my beloved brothers (Munshi Abul Kalam Azad), and (Munshi Abdus Salam) and my 6 sisters (Layla Anjumand Banu (Chandu), Akter Rashida Banu (Turi), Saleha Pervin (Lili), Azmeri Ferdowsi (Dolly), Jannatul Ferdowsi (Polly) and my beloved youngest sister Bedowra Ferdowsi (Jolly), Oysorjo, Omeo, as well as all family members for their inspiration and help.

\section{References}

[1] Awal, M.A. (2007). Analysis of possible environmental factors causing top-dying in mangrove forest trees in the Sundarbans in Bangladesh. $\mathrm{PhD}$ thesis, University of Bradford.

[2] Awal, M.A., Hale, W.H.G. \& Stern, B. (2009). Trace element concentrations in mangrove sediments in the Sundarbans, Bangladesh. Marine Pollution Bulletin, 58(12), 1944-1948.

[3] Awal, M.A. (2014). "Correlation between the chemical composition of the surface sediment and water in the mangrove forest of the Sundarbans, Bangladesh, and the regeneration, growth and dieback of the forest trees and people health"..Journal of Science Innovation; 2014. 2(2): pp.11-21.Science Publishing Group, USA; May 20th, 2014(2):11-21;doi: 10.11648/j/si.20140202.11.

[4] Bakshi, B. K. 1954. Wilt disease of Dalbergia sissoo Roxb due to Fusarium solani Sensu Snyder and Hensen. Natural Nature 174: 278-291.

[5] Balmforth, E. B. 1985. Observation on Sundri top dyingdescriptive Sampling. In the Sundarbans reserved forest. Draft Working Paper, UNDP/FAO Project BGD/77/017, and Dhaka.32 pp.

[6] Bangash, S. H; Gardiner, B. N. 1985. Dieback disease - a cause of boron deficiency in forest trees. The Pakistan Journal of Forestry, 35: 21-29.

[7] Black, et al., 1965. Methods of soil analysis (part 1). Physical and mineralogical properties, including statistics of measurement and sampling. American society of agronomy, Inc., publisher Madison, Wisconsin, USA: 562-566.

[8] Blasco, F. 1975. Mangroves in India. French Institute of Pondicherry. Trav. 14: 1-80.

[9] Blasco, F. (1977). Outlines of Ecology, Botany and Forestry of the Mangals of the Indian sub-continent. In: Wet coastal ecosystem (ed. V.J. Chapman), Elsevier, Amsterdam 13(1), 19(2). 
[10] Chaffey, D. R; Miller, F.R; Sandom, J. H. 1985. A forest inventory of the Sundarbans, Bangladesh, Main report, Project Report No.140, 196 pp; Overseas Development Administration, London, U.K:195-196.

[11] Chaudhury, A.M. (1962). Working Plan of Sundarbans Forest Division, for the period from 1960-61 to 1979-80, Vol I, II, and III. Forest Department.

[12] Chaudhury, A.M. 1968. Working Plan of Sundarbans Forest Division for the period from 1960-61 to 1979-80, 82: East Pakistan Government Press, Dacca.

[13] Chowdhury, J. H. 1973. Preliminary report of the investigation of the top dying of Sundri in the Sundarbans. BFRI, Chittagong, Bangladesh, 2 p.

[14] Christensen, B. 1984. Integrated development of the Sundarbans, Bangladesh: Ecological aspects of the Sundarbans. Reported prepared for the Government of Bangladesh. FAO report no. FO: TCP/ BGD/2309(MF) W/ R0030.

[15] Faizuddin, M. and Islam, S.A. 2003. Generated Technology and Usable Information of the Mangrove Silviculture. Mangrove Silviculture Division, Bangladesh Forest Research Institute

[16] FAO, 1994. Review of the state of world marine fisheries resources. FAO Fisheries resources. FAO Fisheries Technical Approach Paper 335:143.

[17] Fujimoto, K; Miyagi, T; Kikuchi, T; and kawana, T. (1996). Mangrove habitat formation and response to Holocene sealevel changes on kosrae Island, Micronesia. Mangrove and salt marshes, 1:47-57.

[18] Hassan, M. M. 1984. Soil formation in the recent deltaic region of Bangladesh. Bangladesh Journal of Soil Science $20: 37-45$

[19] Hassan, M. M. 1988. Soil and Salinity of the Sundarbans in relation to top dying, regeneration and survival of Sundri. UPR of Bangladesh Forest Research Institute, Chittagong: 9.

[20] Hassan, M. M.; Mazumder, A. H.; Islam, A. T. M. N. and Hossain, A.T. M. E. 1990. Soil, hydrology and salinity of Sundarbans in relation to top dying, regeneration and survival of Sundri (Heritiera fomes) trees. In: Rahaman, M. A.; Khandakar, K.; Ahmed, F.U. and Ali, M.O. (Eds.). Proceedings of the Seminar on Top Dying of Sundri (Heritiera fomes) Trees. Bangladesh Agricultural Research Council, Dhaka: 1- 11.

[21] Imam, S. A. 1982. The Sundarbans and its future. In: proceedings of the Second Bangladesh National Conference on Forestry, Dhaka, Bangladesh, p.19-24.

[22] Jones, G; Battershill, C; and Cole, R. (1992). Marine reserves: do they work? In: C. Battershill (ed.) Proceedings of the International Temperate Reef Symposium, Aucland, New Zealand, p.29-45.

[23] Karim, A. March 1994. Mangrove Silviculture-Volume 1-3. FAO/UNDP (IRDP): 38-140.

[24] King, M. (1995). Fisheries Biology, Assessment and Management. Oxford: Fishing News Books.

[25] Landsberg, T. and Greger, M. 1996. Differences in uptake and tolerance to heavy metals in Salix from unpolluted and polluted areas. Applied Geochemistry 11:175-180.

[26] Landsberg, J. J. and Gower, S.T. 1997. Applications of Physiological ecology to Forest management. Academic Press, San Diego, CA, USA.

[27] Mitra, G. N; and Mohapatra, P. 1954. Mangrove and coastal flora, conservation of fragile ecosystem, Ecology, India, Indian Journal, 2:299-310.

[28] Naskar, K. and Mandal, R. 1999. Ecology and Biodiversity of Indian Mangroves, Publishing House, New Delhi, India, Volume, I \& II, p.21.

[29] Peters, R.L; and Darling, J. D. (1985). The greenhouse effect and nature reserves. Biological Science, 35 (11): $707-$ 717.

[30] Prain, D. 1903. Flora of the Sundarban. Records of the Botanical Survey of India. Periodical Expert Book Agency, Delhi.pp.231-370.

[31] Rahman, M.A. 2003. Genetic Approach to mitigate the top Dying Problem of Heritiera fomes in the Mangrove Forests, Khulna University, Bangladesh, 87pp.

[32] Seidensticker, J. Hai; A. 1983. The Sundarbans wildlife managemen plan: conservation in the Bangladesh (cited in Chaffey et al., 1985), Bangladesh.

[33] Seidensticker, J. 1986. Large Carnivores and the consequences of habitat insularization, Ecology and conservation of tigers in Indonesia and Bangladesh. In: Cats of the World: Biology, Conservation \& management. (Eds. S D. Miller \& D.D. Eveutt). Wetidal Wildlife Federation, Washington DC, p. 1-41.

[34] Seidensticker, J. \& Hai, M.A. 1983. The Sundarbans Wildlife Management. Bangladesh coastal zone. International Union for Conservation of Nature. Gland, Switzerland.

[35] Seidensticker, J.; Christie, S. \& Jackson, P.1999. Introducing the tiger. Cambridge University press, London, p.1-3.

[36] Shahidullah, M.1980. Salinity penetration on the south-west of Bangladesh: Impact of reduced low flow of the major rivers of Bangladesh (Seminar).Mimeographed report.10 pp.

[37] Snedakar, S .C. 1984. General Ecology: Resource Utilization Potential for the Bangladesh, Dhaka, Bangladesh: 31 .

[38] Snedaker, S.C. 1977. General Ecology and Resource Utilization Potential of the Sundarbans, FAO Report No.Fo:TCP/BGD/2309 (MF) W/R, 28 prepared for the Government of Bangladesh, Dhaka: 31.

[39] Tamang, K. M. 1993. Wildlife Management Plan for the Sundarbans Reserved Forest. Integrated Resource Development of the Sundarbans Reserve Forest. UNDP /FAO, BGD/84/056, Khulna, Bangladesh.

[40] Thom, B.G.1982. Mangrove ecology- a geo-morphological perspective. 1982, p.3-17.

[41] Tiner, R. W; J R. (1984). Wetlands of the United States: Current Status and Recent Trends. Newton Corner, Massachusetts: U.S. Fish and Wildlife Service, Habitat Resources. 
[42] Troup, R.S. 1921. The Silviculture of Indian Trees-Volume 1. Clarendon Press, Oxford: 153-544.

[43] UN-ESCAP, 1987. Final Report: Volume 2. Coastal environment management plan for Bangladesh. Bangkok, Thailand.

[44] UN-ESCAP, 1988. Coastal environment management plan for Bangladesh. Bangkok, Thailand: 7-34.
[45] UNESCO, 1997. Convention Concerning the Protection of the World Cultural and Natural Heritage, France, Paris.

[46] WHO, 1981. Resistance of Disease vectors to pesticides. World Health Organisation, Chronicle, 35, 143.

[47] WFB, 2006. The world fact book-Bangladesh. Population of Bangladesh, Wild Fact Book: 2-3. 